\title{
Mechanisms underlying the emergence of Up and Down states in a model PFC microcircuit
}

\author{
Daphne Krioneriti ${ }^{1,2^{*}}$, Athanasia Papoutsi ${ }^{1,3}$, Panayiota Poirazi ${ }^{1}$ \\ From Twentieth Annual Computational Neuroscience Meeting: CNS*2011 \\ Stockholm, Sweden. 23-28 July 2011
}

Up and Down states are oscillations between periods of prolonged activity (Up state) and quiescence (Down state) and are recorded both in vivo and in vitro in layer $\mathrm{V}$ prefrontal cortex (PFC) pyramidal neurons. Biophysical mechanisms that have been proposed to underlie this phenomenon include the balance of excitation and inhibition within local PFC networks [1] along with certain intrinsic membrane mechanisms such as the afterdepolarization [2]. Using a biophysical compartmental network model of PFC layer V pyramidal neurons that incorporates anatomical data (as described in [3]), we investigated the role of synaptic input, intrinsic currents and local interconnectivity in the following features of Up and Down states: (a) the emergence of Up and Down states, (b) the duration of Up states, (c) the frequency of Up states and (d) the firing frequency during the Up state.

We found that Up and Down states could emerge in our model microcircuit (see Figure 1), provided the existence of background synaptic activity. Among the various conditions we examined, statistically significant results were obtained when:

- Increasing the firing frequency of the background synaptic input or the number of activated background synapses (Up frequency increased by $\sim 150 \%$ and $60 \%$, respectively, firing frequency increased by $\sim 30 \%$ and $50 \%$, respectively).

- Blocking the NMDA current, while compensating for the reduced excitability by enhancing the AMPA current (no emergence of Up and Down states).

\footnotetext{
* Correspondence: dkrioneriti@med.uoc.gr

${ }^{1}$ Computational Biology Lab (CBL), Institute of Molecular Biology and Biotechnology (IMBB), Foundation for Research and Technology-Hellas (FORTH), Heraklion, Crete, GR 711 10, Greece

Full list of author information is available at the end of the article
}

- Increasing the iNMDA-to-iAMPA ratio from 1 to 1.5 (Up frequency increased $\sim 190 \%$, firing frequency increased by $25 \%$, Up duration doubled).

- Activating the dADP mechanism at a physiological value $(4 \mathrm{mV})$ (Up frequency increased by 200\%, firing frequency increased by $60 \%$, Up duration doubled).

\section{Conclusions}

Our results indicate that the generation of Up states in PFC is likely to involve not only a balance of excitation/ inhibition provided within a microcircuit but also single-neuron dynamics shaped by intrinsic mechanisms. Interestingly, the duration of the Up state was significantly altered in only two of the conditions tested, namely, the enhancement of the NMDA current and the activation of the dADP mechanism. These findings suggest that the transition to more prolonged

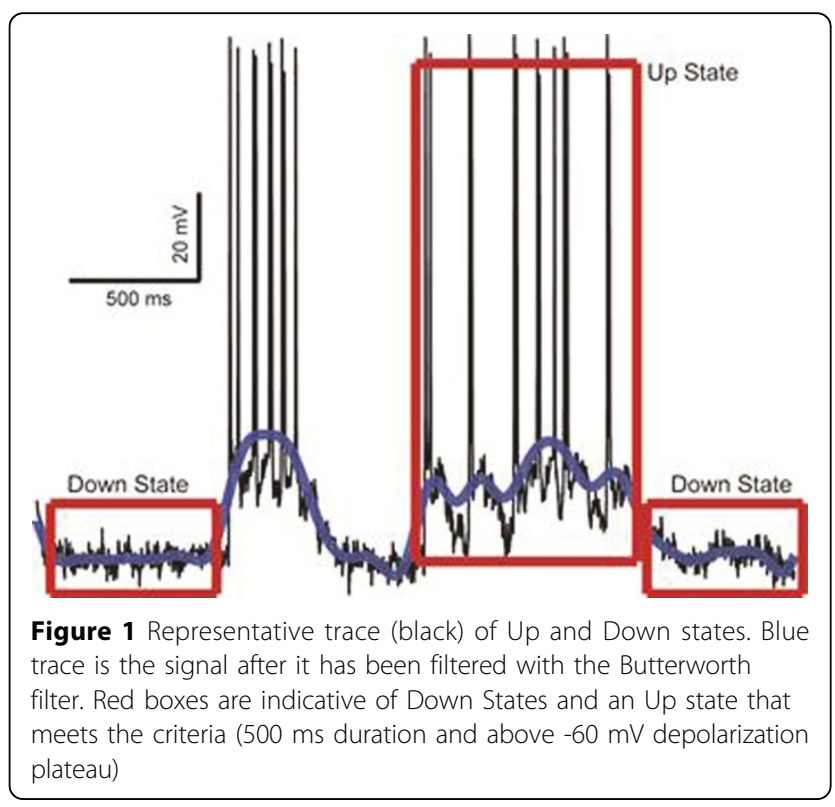


depolarizations is carefully controlled by the same mechanisms that have been associated with persistent firing during working memory tasks.

\section{Author details}

${ }^{1}$ Computational Biology Lab (CBL), Institute of Molecular Biology and Biotechnology (IMBB), Foundation for Research and Technology-Hellas (FORTH), Heraklion, Crete, GR 711 10, Greece. ²Faculty of Medicine, University of Crete, Heraklion, Crete, GR 710 03, Greece. ${ }^{3}$ Biology Department,

University of Crete, Heraklion, Crete, GR 714 09, Greece.

Published: 18 July 2011

\section{References}

1. Shu Y, Hasenstaub A, McCormick DA: Turning on and off recurrent balanced cortical activity. Nature 2003, 423(6937):288-293.

2. Sidiropoulou K, Lu FM, Fowler MA, Xiao R, Phillips C, Ozkan ED, Zhu MX, White FJ, Cooper DC: Dopamine modulates an mGluR5-mediated depolarization underlying prefrontal persistent activity. Nat Neurosci 2009, 12(2):190-199.

3. Papoutsi A, Sidiropoulou K, Poirazi P: Mechanisms underlying persistent activity in a model PFC microcircuit. 2009, 10:P42.

doi:10.1186/1471-2202-12-S1-O7

Cite this article as: Krioneriti et al: Mechanisms underlying the emergence of Up and Down states in a model PFC microcircuit. BMC Neuroscience 2011 12(Suppl 1):07.

\section{Submit your next manuscript to BioMed Central} and take full advantage of:

- Convenient online submission

- Thorough peer review

- No space constraints or color figure charges

- Immediate publication on acceptance

- Inclusion in PubMed, CAS, Scopus and Google Scholar

- Research which is freely available for redistribution

Submit your manuscript at www.biomedcentral.com/submit 